\title{
Relationship of Comorbidity, Age and Perioperative Complications in Patients Undergoing Radical Prostatectomy
}

\author{
Michael Froehner ${ }^{a}$ Rainer Litz ${ }^{b}$ Andreas Manseck ${ }^{a}$ Oliver W. Hakenberg ${ }^{a}$ \\ Steffen Leike ${ }^{a}$ D.-Michael Albrecht ${ }^{b}$ Manfred P. Wirth ${ }^{a}$ \\ Departments of a Urology and 'Anesthesiology, University Clinics 'Carl Gustav Carus', \\ Technical University of Dresden, Germany
}

\author{
Key Words \\ Comorbidity $\cdot$ Selection $\cdot$ Prostate cancer $\cdot$ Radical \\ prostatectomy $\cdot$ Clinical trials $\cdot$ Complications
}

\begin{abstract}
Objectives: To investigate the prevalence and distribution of comorbidity and its association with perioperative complications in patients undergoing radical prostatectomy (RPE). Methods: In 431 unselected RPE patients, the American Society of Anesthesiologists Physical Status classification (ASA-PS), the New York Heart Association classification of cardiac insufficiency (NYHA), the classification of angina pectoris of the Canadian Cardiovascular Society (CCS), height, weight, the body mass index (BMI), and the number of concomitant diseases (NCD) were assessed and related to perioperative cardiovascular complications. Results: In RPE patients less than 70 years old, comorbidity rose nearly continuously with increasing age. However, after reaching an age of 70 years, the proportion of NYHA-0 patients increased (60-64 years, 86\%; 65-69 years, $85 \%$; $\geq 70$ years, $87 \%$ ). Furthermore, the severe comorbidities decreased in patients selected for RPE aged 70 or more years. There was a nonsignificant trend towards higher comorbidity in patients with perioperative cardiovascular complica-
\end{abstract}

\section{KARGER}

Fax +41613061234 E-Mail karger@karger.ch www.karger.com
(C) 2001 S. Karger AG, Basel

0042-1138/01/0674-0283\$17.50/0

Accessible online at:

www. karger.com/journals/uin tions. Conclusions: These data suggest that documentation of the distribution of ASA-PS, CCS, NYHA and of concomitant diseases might be helpful to characterize the general health status and the degree of selection of prostate cancer treatment populations especially in series with a high portion of patients aged 70 or more years. Concerning perioperative complications, the individual predictive value of comorbidity seems to be poor in the radical prostatectomy setting.

Copyright $\odot 2001$ S. Karger AG, Basel

\section{Introduction}

Traditionally, an age of 70 years has been considered as a limit for patients to be candidates for radical prostatectomy $[1,2]$. During the last years, however, the procedure has become increasingly popular in elderly patients. In a contemporary series [3], more than half of the patients were 70 years old or older. Although comorbidity considerably influences survival [4], few data are available on the prevalence of concomitant diseases in prostate cancer patients. Some studies dealt with comorbidity in screening populations [5], unselected newly diagnosed prostate cancer patients [6], and with the influence of comorbidity on the life expectancy of conservatively

Michael Froehner, MD, Department of Urology

University Clinics 'Carl Gustav Carus', Technical University of Dresden

Fetscherstrasse 74, D-01307 Dresden (Germany)

Tel +49 3514582447, Fax +49 3514584333

E-Mail Michael.Froehner@mailbox.tu-dresden.de 
Fig. 1. Distribution of ASA-PS in patients undergoing RPE in the 5 age groups and among patients without and with cardiovascular complications. After a fairly continuous increase, the portion of ASA-PS 3 patients decreased after reaching an age of 70 or more years. ASA-PS 3 seemed to be slightly overrepresented in patients with cardiovascular complications.

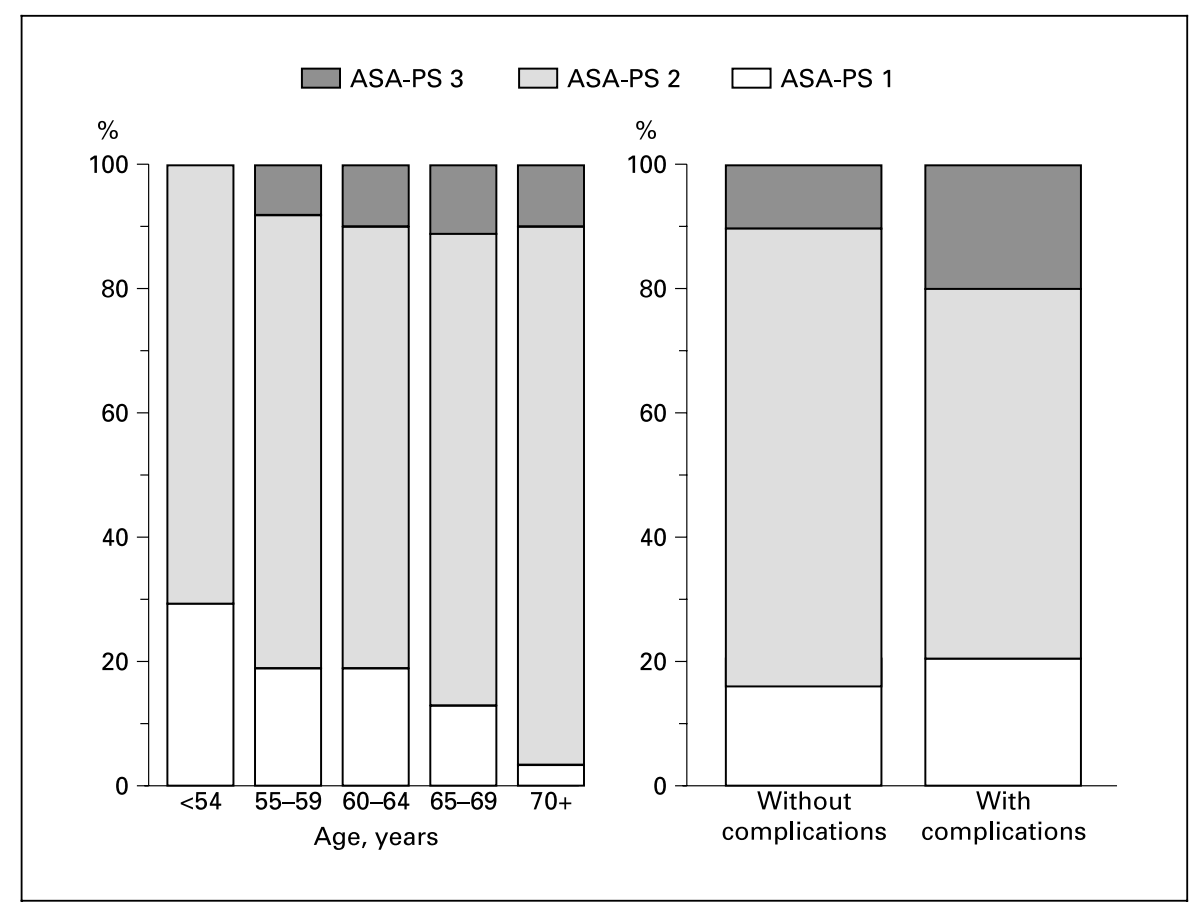

treated prostate cancer patients [4]. However, only few series with comorbidity information in patients undergoing radical prostatectomy have been reported $[7,8]$. To our knowledge, only one study investigated the relationship between comorbidity and perioperative complications in the radical prostatectomy setting [8]. In this study, we assessed the prevalence and distribution of concomitant diseases and perioperative complications in 431 radical prostatectomy patients.

\section{Materials and Methods}

The records of 433 unselected patients (mean age 63.5, range 4575 years) who underwent radical prostatectomy at a single center in the years 1992-1999 were retrospectively reviewed. Patients were enrolled into this study according to their availability in a database designed to study different anesthetic procedures [9]. Two patients were excluded from analysis because of incomplete data. Data concerning comorbidity classifications (American Society of Anesthesiologists Physical Status classification (ASA-PS, six categories 1-6); New York Heart Association classification of cardiac insufficiency (NYHA, five categories 0-4), and the classification of angina pectoris of the Canadian Cardiovascular Society (CCS, four categories 1-4)), height, weight, and body mass index (BMI) were taken from the anesthesiologic premedication records and were checked by chart review and (in the case of CCS) by review of the preoperative electrocardiogram. Six concomitant diseases were recorded from both the premedication form and the patient chart: cardiac insufficiency (NYHA
$>1$ ), hypertension, diabetes, history of thromboembolism, chronic obstructive and restrictive pulmonary disease. The number of concomitant diseases (NCD) was calculated for each patient from these data and compared between patients with ASA-PS 1, 2, and 3, respectively, using Student's t test. Patients aged $<70$ years were compared with those aged $\geq 70$ years by comorbidity (ASA-PS, NYHA, CCS, NCD), height, weight, and BMI with $\chi^{2}$ or Student's t test. Two general types of perioperative complications were discriminated: cardiovascular complications (any perioperative death, venous thrombosis, thromboembolism, myocardial infarction, pulmonary edema), and miscellaneous complications (such as wound infection, diarrhea, insignificant cardiac arrhythmia, pneumonia, pelvic lymphoceles). The relationship between comorbidity and cardiovascular complications was investigated by univariate $\left(\chi^{2}\right.$ or the Student's t test) and multivariate (logistic regression) analysis.

\section{Results}

Whereas the BMI decreased, all investigated comorbidities (ASA-PS, range 1-3; NYHA, range 0-3; CCS, range $0-3$; NCD, range $0-4$ ) rose nearly continuously with increasing age in patients less than 70 years old (fig. 1-4). However, after reaching the age of 70 years, the prevalence of cardiac insufficiency (NYHA) fell slightly, and the proportion of NYHA-0 patients increased (fig. 2). Furthermore, the proportion of severe comorbidities (ASA-PS 3, NCD >1) decreased (fig. 1, 4). The portion of 
Fig. 2. Distribution of cardiac insufficiency (NYHA) in patients undergoing RPE in the 5 age groups and among patients without and with cardiovascular complications. After a fairly continuous decrease, the portion of NYHA 0 patients increased after reaching an age of 70 or more years. Cardiac insufficiency seemed to be slightly overrepresented in patients with cardiovascular complications.

Fig. 3. Distribution of angina pectoris (CCS) in patients undergoing RPE in the 5 age groups and among patients without and with cardiovascular complications. There was a continuous, possibly slightly progressive increase in the prevalence of angina pectoris over all 5 age groups. Angina pectoris seemed to be slightly overrepresented in patients with cardiovascular complications.
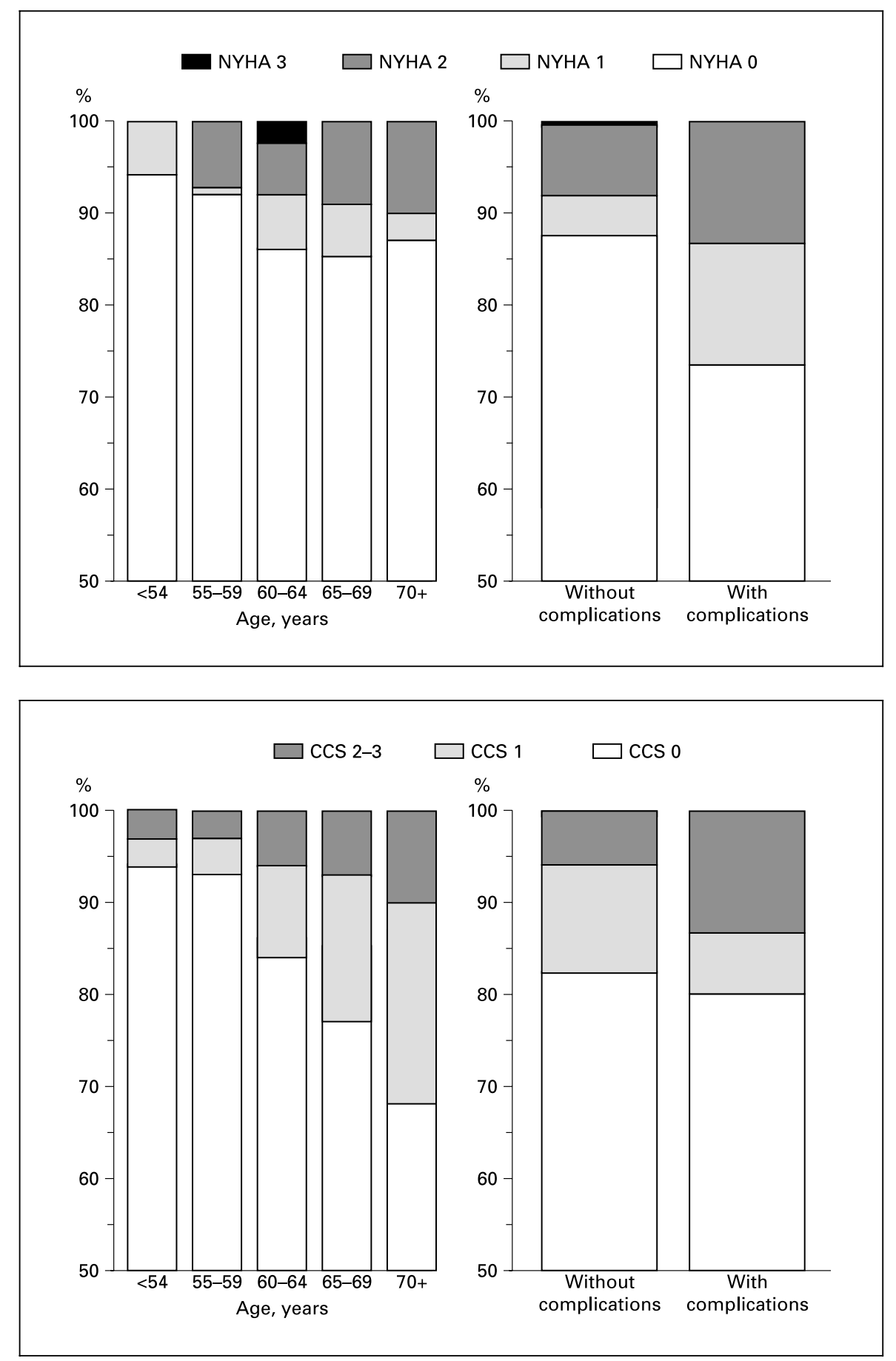

patients aged 70 or more years (overall 14\%) increased from $10 \%(\mathrm{NCD}=0)$ to $18 \%(\mathrm{NCD}=1)$, but fell to $17 \%$ $(\mathrm{NCD}=2)$ and $6 \%$ in patients with $\mathrm{NCD}=3-4$. There was a tendency towards higher comorbidity in patients aged 70 or more years compared with younger men; how- ever, only the categories ASA-PS $(\mathrm{p}=0.049)$ and CCS $(\mathrm{p}=$ $0.0029)$ reached statistical significance. Mean height (172 versus $174 \mathrm{~cm}, \mathrm{p}=0.049$ ) and weight ( 77 versus $80 \mathrm{~kg}, \mathrm{p}=$ 0.049 ) were significantly lower in patients aged 70 or more years compared with younger patients. Concerning 
Fig. 4. Distribution of the number of concomitant diseases (NCD) in patients undergoing RPE in the 5 age groups and among patients without and with cardiovascular complications. In patients aged less than 70 years, the prevalence of concomitant diseases rose fairly continuously with age. Beyond this limit, however, the portion of patients with 2 or more concomitant diseases decreased. Concomitant diseases seemed to be slightly overrepresented in patients with cardiovascular complications.

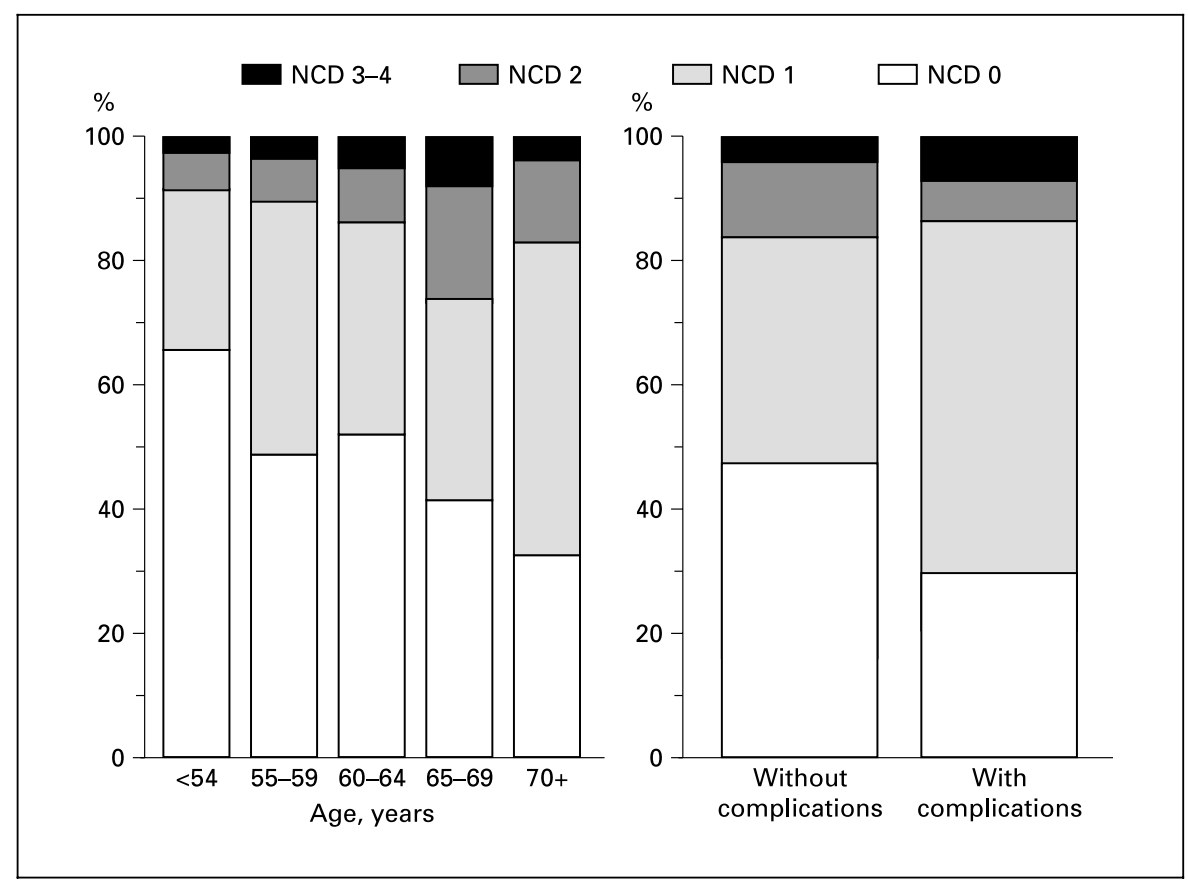

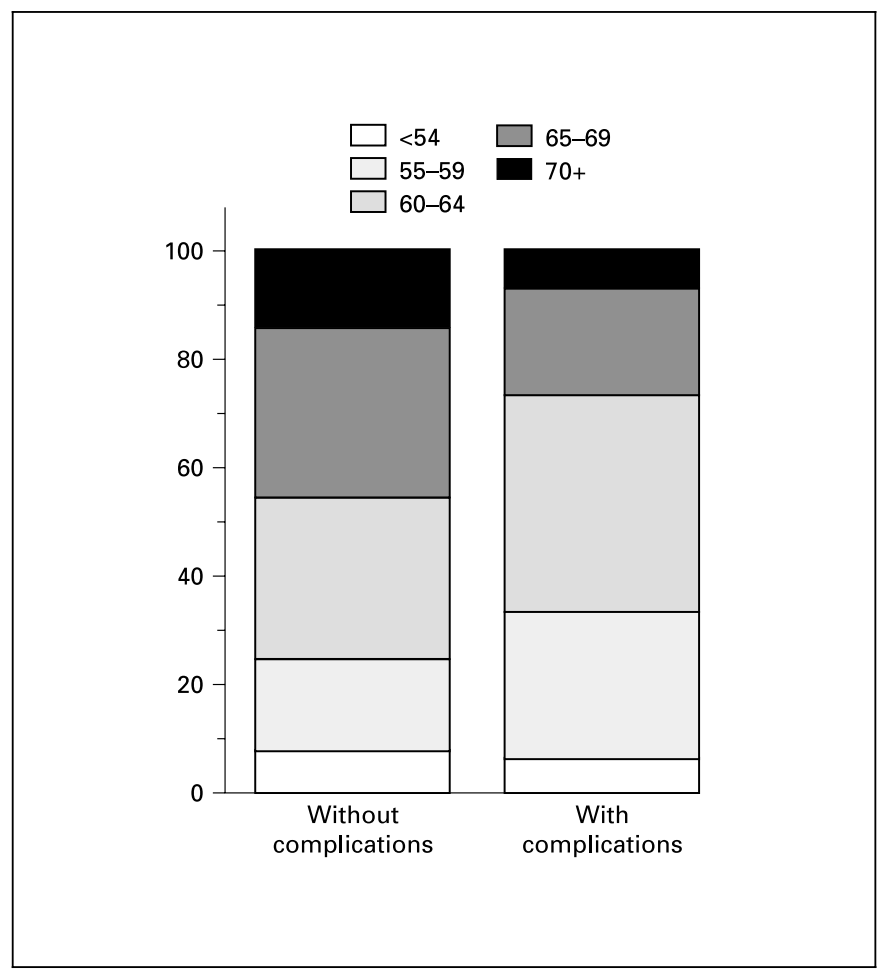

Fig. 5. Distribution of the 5 age groups among patients without and with cardiovascular complications. Patients aged 65 or more years seemed to be slightly underrepresented in the group with cardiovascular complications.
BMI, statistical significance was not reached (25.8 versus $\left.26.5 \mathrm{~kg} / \mathrm{m}^{2}, \mathrm{p}=0.135\right)$. The NCD differed significantly between patients with ASA-PS $1(\mathrm{n}=68$, mean NCD $=$ $0.00, \mathrm{p}<0.0001)$, ASA-PS $2(\mathrm{n}=324$, mean $\mathrm{NCD}=0.75$, $\mathrm{p}<0.0001)$ and ASA-PS $3(\mathrm{n}=39$, mean NCD $=1.90, \mathrm{p}<$ 0.0001).

Perioperative complications were recorded in 98 patients. 15 events were considered cardiovascular complications: 3 deaths within 30 days postoperatively ( 1 immediately postoperatively, 2 shortly after discharge from the hospital); one myocardial infarction; 3 pulmonary embolisms; 7 venous thromboses, and 1 pulmonary edema. Taking all recorded complications together, the distribution of age and comorbidities was nearly the same between patients with and without complications. Focussing on cardiovascular complications, however, there was a trend towards higher comorbidity (ASA-PS, NYHA, CCS, NCD) in patients with such complications (fig. 14). However neither univariate nor multivariate analysis revealed statistically significant differences. There was no significant age difference between patients with (mean age 62.2 years) and without cardiovascular complications (mean age 63.5 years). Considering the age distribution, there seemed to be a (nonsignificant) trend towards underrepresentation of elderly patients in the group with cardiovascular complications (fig. 5). 
Table 1. Age-related height, weight, BMI, and distribution of concomitant diseases among 431 radical prostatectomy patients

\begin{tabular}{|c|c|c|c|c|c|c|c|c|c|c|c|}
\hline $\begin{array}{l}\text { Age group } \\
\text { years }\end{array}$ & $\mathrm{n}$ & $\begin{array}{l}\text { Mean } \\
\text { NCD }\end{array}$ & $\begin{array}{l}\text { CI } \\
\text { (NYHA } \\
2 \text { or } 3), \%\end{array}$ & $\begin{array}{l}\text { Hyper- } \\
\text { tension } \\
\%\end{array}$ & $\begin{array}{l}\text { Diabetes } \\
\%\end{array}$ & $\begin{array}{l}\text { History of } \\
\text { thrombo- } \\
\text { embolism, \% }\end{array}$ & $\begin{array}{l}\text { COPD } \\
\%\end{array}$ & $\begin{array}{l}\text { RPD } \\
\%\end{array}$ & $\begin{array}{l}\text { Mean body } \\
\text { weight, kg }\end{array}$ & $\begin{array}{l}\text { Mean body } \\
\text { height, cm }\end{array}$ & $\begin{array}{l}\text { Mean } \\
\text { BMI } \\
\mathrm{kg} / \mathrm{m}^{2}\end{array}$ \\
\hline$<54$ & 35 & 0.46 & 6 & 23 & 6 & 0 & 9 & 3 & 82 & 175 & 26.8 \\
\hline $55-59$ & 73 & 0.63 & 7 & 39 & 10 & 0 & 7 & 1 & 82 & 175 & 26.7 \\
\hline $60-64$ & 131 & 0.66 & 8 & 43 & 9 & 1 & 5 & 0 & 80 & 174 & 26.5 \\
\hline $65-69$ & 132 & 0.89 & 9 & 52 & 14 & 6 & 8 & 0 & 79 & 174 & 26.3 \\
\hline $70+$ & 60 & 0.87 & 10 & 52 & 13 & 2 & 8 & 2 & 77 & 172 & 25.8 \\
\hline Overall & 431 & 0.74 & 8 & 44 & 11 & 2 & 7 & 1 & 80 & 174 & 26.4 \\
\hline
\end{tabular}

$\mathrm{CI}=$ Cardiac insufficiency; $\mathrm{COPD}=$ chronic obstructive pulmonary disease; $\mathrm{RPD}=$ restrictive pulmonary disease.

\section{Discussion}

Since prostate cancer is mostly a slowly progressing disease of old age, comorbidity and patient selection have significant implications for the interpretation of clinical trials $[4,10]$. Nevertheless, only few data are available on the prevalence of comorbidities in prostate cancer patients [6]. Data from studies addressing comorbidity in prostate cancer vary in the way data were collected and in the choice of conditions recorded. Post et al. [6] reported comorbidity data from newly diagnosed prostate cancer patients from the southern Netherlands. Compared with their data, there was a lower portion of patients without any concomitant disease in all age groups in our sample. However, the authors [6] did not record hypertension as a comorbidity, which accounted for more than a half of the concomitant diseases in our study group (table 1). When hypertension is excluded, the subgroup without comorbidity was nearly the same in patients aged less than 60 years as in the cited study [6], whereas in men aged more than 60 years there was an even lower comorbidity in our study. It is, however, unclear whether this difference does really exist or whether it may be attributed to differences in study design. Compared to elderly male participants of the Canada Health Survey (questionnaire-based, mean age 66.6 years) [5], in our series the proportion of men without any comorbidies was equal in patients aged 6069 years and lower in those aged 70 or more years. This possibly reflects the selection in favor of good risks in this subgroup. Considering radical prostatectomy series with available comorbidity data, in a study by Koch and Smith [11] $(\mathrm{n}=109$, mean age 62 years) the prevalence of diabetes was equal to that in our series (11\% [11]), whereas hypertension (26 [11] versus 44\%) and chronic obstruc- tive pulmonary disease (1 [11] versus $7 \%$ ) were less frequent. Among men aged 60 or more years in the Canada Health Survey [5], emphysema/chronic bronchitis $(9.3 \%)$ and hypertension $(36.6 \%)$ were similarily as common as in our study (fig. 5). This suggests an elimination by selection or an underreporting of these two conditions in the cited series [11]. In another study [7], comorbidity information was derived from hospital records of 138 radical prostatectomy patients (median age 64.5 years) and of 138 patients (median age 69.0 years) undergoing radiotherapy. Compared with our series, chronic pulmonary disease and diabetes were less common in the radical prostatectomy group; however, these diseases were considerably overrepresented in the radiotherapy group, obviously due to a selection effect. Combining both groups, the frequency of both conditions was nearly equal in the (somewhat elderly) population of Fowler et al. [7] and in our series (diabetes 12 [7] versus $11 \%$, chronic pulmonary disease 8 [7] versus $8 \%$ ).

Three groups provided ASA-PS classification data for patients undergoing radical prostatectomy $[8,11,12]$. The age distribution in these series was almost the same as in our study. Concerning the distribution of patients with ASA-PS 3, our data (fig. 1) are similar to those reported by Dillioglugil et al. [8] who also found a fairly linear increase of the percentage of patients with ASA-PS 3 below an age of 70 years followed by a decrease in the patients aged 70 or more years. The proportion of ASA-PS 3 patients was, however, higher in all three studies cited (16\% [8], 23\% [11], 27.8\% [12]), compared with our series (9\%). It is not clear whether these conflicting results were really caused by differences between the study populations or whether they were due to different classification standards. In order to achieve comparability, it seems to be necessary to 
collect more detailed and objective information on special health aspects such as the prevalence of other diseases (the mean NCD differed highly significantly between the ASA-PS classifications in our series) and heart function (NYHA, CCS), especially since these comorbidities seemed to represent selection criteria in our series. It was conspicuous that, beyond the traditional radical prostatectomy age limit of 70 years, the proportion of NYHA-0 patients increased after a fairly continuous decrease up to this point (fig. 2). Furthermore, patients over 70 years old were underrepresented on the subgroup with severe comorbidity (NCD >1; fig. 4). ASA-PS, NYHA and NCD were obviously selection criteria in patients over 70 years old. The decreasing BMI reflects the tendency of body weight to decrease after an age of 60 years [13] and should not be attributed to selection.

In contrast to the study by Dillioglugil et al. [8], which found a significant association between comorbidity (ASA-PS) and major perioperative complications, statistical significance was not reached in our study. It is, however, likely that such a relationship exists, since there seemed to be a trend towards higher comorbidities in all four classifications assessed (ASA-PS, NYHA, CCS, NCD) in patients with cardiovascular complication (fig. 1-4). In our series, $9 \%$ of patients were classified as ASA-PS 3 (16\% in the series of Dillioglugil et al. [8]), possibly reflecting a more favorable risk profile in our series requiring a higher number of patients to identify differences. Furthermore, Dillioglugil et al. [8] used a meticulous severity score for adverse events which we considered not applicable to our retrospective series.

In conclusion, patients aged 70 or more years have been shown to be likely to have undergone selection by exclusion of severe comorbidities (ASA-PS3 or NCD $>1=$ exclusion from radical prostatectomy) and selection of patients with excellent heart function (NYHA $0=$ encouragement to undergo radical prostatectomy despite advanced age). In any radical prostatectomy study populations with a high portion of patients aged 70 or more years, the additional documentation of the distribution of concomitant diseases and of any impairment of heart function (CCS, NYHA) might be helpful to enable comparability of the general health status, which is likely to affect outcome. Despite a possible trend towards higher comorbidity in patients with cardiovascular complications, the individual predictive value seems to be poor in appropriately selected radical prostatectomy patients.

\section{Acknowledgement}

The authors thank Prof. Rainer Koch, Department of Medical Statistics of the Technical University of Dresden, for his assistance in performing the statistical analysis.

\section{References}

1 Middleton AE: Radical prostatectomy for carcinoma in men more than 69 years old. J Urol 1987; 138:1185-1188.

2 Catalona WJ, Ramos GR, Carvalhal GF: Contemporary results of anatomic radical prostatectomy. CA Cancer J Clin 1999;49:282-296.

3 Benoit RM, Naslund MJ, Cohen JK: Complications after radical retropubic prostatectomy in the Medicare population. Urology 2000;56: 111-120.

4 Albertsen PC, Fryback DG, Storer BE, Kolon $\mathrm{TF}$, Fine $\mathrm{J}$ : The impact of co-morbidity on life expectance among men with localized prostate cancer. J Urol 1996;156:127-132.

5 Eapen L, Villeneuve PJ, Levy IG, Morrison HI: Comorbid survival among elderly participants of the Canada health survey: Relevance to prostate cancer screening and treatment. Chronic Dis Can 1998;19:84-90.
6 Post PN, Kil PJM, Hendrikx AJM, JanssenHeijnen MLG, Crommelin MA, Coebergh JWW: Comorbidity in patients with prostate cancer and its relevance to treatment choice. BJU Int 1999;84:652-656.

7 Folwer JE, Terrell FL, Renfroe DL: Co-morbidities and survival of men with localized prostate cancer treated with surgery or radiation therapy. J Urol 1996;156:1714-1718

8 Dillioglugil Ö, Leibman BD, Leibman NS, Kat$\tan$ MW, Rosas AL, Scardino PT: Risk factors for complications and morbidity after radical retropubic prostatectomy. J Urol 1997;157: 1760-1767.

9 Heller AR, Litz RJ, Djonlagic I, Manseck A, Koch T, Wirth MP, Albrecht DM: Kombinierte Anästhesie mit Epiduralkathether. Eine retrospektive Analyse des perioperativen Verlaufs bei Patienten mit radikalen Prostatektomien. Anaesthesist 2000;49:949-959.
10 Albertsen PC, Fryback DG, Storer BE, Kolon $\mathrm{TF}$, Fine J: Long-term survival among men with conservatively treated localized prostate cancer. JAMA 1995;275:626-631.

11 Koch MO, Smith JA: Influence of patient age and co-morbidity on outcome of a collaborative care pathway after radical prostatectomy and cystoprostatectomy. J Urol 1996;155: 1681-1684

12 Hautmann RE, Sauter TW, Wenderoth UK: Radical retropubic prostatectomy: Morbidity and urinary continence in 418 consecutive cases. Urology 194;43(suppl):47-51.

13 Seidell JC, Visscher TL: Body weight and weight change and their health implications for the elderly. Eur J Clin Nutr 2000;54(suppl 3): S33-S39. 